\title{
Issue of Theory and Practice Discrepancy in Digital Economy Development
}

\author{
Gryaznova E.V.* \\ Minin Nizhny Novgorod State Pedagogical University \\ Nizhny Novgorod, Russia \\ E-mail: egik37@yandex.ru
}

\section{Maltseva S.M.}

Minin Nizhny Novgorod State Pedagogical University Nizhny Novgorod, Russia

E-mail: maltsewasvetlana@yandex.ru

\section{Borisova I.I}

University Pierre Mendes

Grenoble, France

Lobachevsky State University of Nizhny Novgorod

Nizhny Novgorod, Russia

E-mail: irenbor90@yandex.ru

\author{
Goncharuk A.G. \\ Minin Nizhny Novgorod State Pedagogical University \\ Nizhny Novgorod, Russia \\ E-mail: aleksgon75@gmail.com
}

\author{
Pronina S.V. \\ Lobachevsky State University of Nizhny Novgorod \\ Nizhny Novgorod, Russia \\ E-mail: proswet5@yandex.ru
}

\author{
Bulganina S.V. \\ Minin Nizhny Novgorod State Pedagogical University \\ Nizhny Novgorod, Russia \\ E-mail: bulgsv@mail.ru
}

\begin{abstract}
The concept of "digital" economy is becoming one of the most common terms used to refer to economic processes and activities in the economic sphere of the information society. However, its meaning is ambiguous. The scientific, economic and regulatory literature has developed different approaches to its interpretation. Understanding the essence of the digital economy as a phenomenon is especially important for regulatory documents, as they serve as a guide to action. It is in them, as studies show, that inaccuracies and ambiguities in the definition of the digital economy in our country are allowed. Turning to scientific research in the field of economics shows that scientists point out possible negative consequences of an inaccurate understanding of the essence of the phenomenon, which is the basis of the quality of life of the country's population. To mitigate these consequences, it is necessary to conduct systematic studies of the phenomenon of the digital economy with a complex of sciences, such as philosophy, sociology, economics and social management.
\end{abstract}

Keywords - digital economy, information economy, economic activity, knowledge economy.

\section{INTRODUCTION}

Categorical analysis is an integral part of scientific research. As it is known, any scientific knowledge has five main criteria. Subjectology - the definition and development of the subject of research. Terminology - the development of their own categorical apparatus. Methodology - the definition and justification of the research methodology. Nomology - the study of laws and principles. Finally, praxeology is the way to practice [11]. The digital economy today claims the right to self-determination as an independent branch of knowledge. Like any scientific field, it experiences difficulties, first of all, in determining its own terminological apparatus and subject field. On the one hand, it is necessary to find out whether the digital economy is a specific branch of economic knowledge. On the other hand, in the era of the development of the information society, the entire economy should switch to digital technologies, and then we should speak of a qualitative leap in the change of economic knowledge and the economy as a branch of the national economy.

The discussions on this subject today are being conducted on the pages of not only publications on economics, but also in the works of social and humanitarian knowledge. The most pressing issue that researchers are interested in is the question of the concept and essence of the digital economy. Developed and applied programs for its development will depend on an understanding of the specifics of this phenomenon, its nature. Therefore, the subject of this article is a discussion about understanding the digital economy in legal acts and scientific knowledge.

\section{RESEARCH METHODOLOGY}

As the main research methods in the work we used the method of analytical research of regulatory documents and scientific papers, the principles of dialectics, the method of analysis, comparison and generalization.

\section{A. Interpretation of the concept of "digital economy" in the regulatory documents of Russia.}

The concept of "digital economy" is often used not only in scientific publications, but also in regulatory documents. However, the definition of this concept has not yet received a single understanding and interpretation.

To begin with, we turn to official documents, which are the source of new terms and concepts in the field of the digital 
economy. For example, in the national program of Russia, the following definition is given: "... the digital economy is an economic activity, the key production factor of which is digital data" [33].

The document "Development Strategy of the Information Society in the Russian Federation for 2017-2030", which is the basis for the national program for the development of the digital economy, gives a broader definition of this phenomenon: “... the digital economy is an economic activity in which the key production factor is digital form, the processing of large volumes and the use of analysis results which compared with traditional forms of management can significantly increase the efficiency of different all types of production, technologies, equipment, storage, sale, delivery of goods and services" [7].

\section{B. Definition of "digital economy" in the scientific and economic literature.}

Now consider the content of the concept of "digital economy" in the scientific and economic literature. In our discussion, we will precede from the grounds, or rather the reasons for the emergence of the concept of the digital economy. One of them we consider the concept of postindustrial society. It is sufficiently capaciously disclosed in the works of both foreign and domestic authors. Of course, the primacy in this matter belongs to foreign scientists. Here we should mention the works of M. Castells [6], M. McLuhan [21], E. Toffler [35], D. Bell [5] and others. Among the Russian scientists, these are the works of N.N. Moiseev [22], A.I. Rakitov [29], R.F. Abdeev [1] and others.

The term "digital economy" was introduced by N. Negroponte in 1995 and had the following meaning: in the new economy there will be a transition from paper to electronic media (Negroponte, 1996). In the future, this concept acquires several interpretations: “... the digital economy is "the economy based on digital technologies is exclusively the field of electronic goods and services" such as telemedicine, distance learning, and the sale of media content" [20]. According to the second approach: "the digital economy is an economic production using digital technologies", including the creation of the Internet of things, Industry 4.0, a smart factory etc. [20]. In the framework of these definitions, the digital economy is a sector of the economy that uses information technology.

The question arises: can there be any other economy in the information society? If we are still talking about the state, and not about personal subsidiary plots, then it is unlikely. Then it is fair to name a new type of information economy [12, 32]. In this case, we are not talking about the economic sector, but about the fact that the whole economy should go digital, otherwise economic relations will not be able to exist and develop in the conditions of informatisation and globalization.

The category "information economy" is found in the works of the late 20th century, for example, in the works of M. Porat. In particular, he understands it as "the economy of information benefits and information and communication technologies" [27]. In this case, we are still talking about the priority importance of information and knowledge in managing the economy in the information age, and not about highlighting a special digital sector of the economy. Another thing is that the isolation of such a sector was nevertheless predicted, and a completely different role was assigned to it. As we know, this phenomenon was given another name - the fourth sector of the economy, along with the areas of production, agriculture and services. One way or another, it was about "trading" information and knowledge in the information society, the capitalization of these phenomena [16].

Thus, another version of the interpretation of the "digital economy" has become widespread - the knowledge economy $[28,31])$. Initially, the knowledge economy was defined as an independent sector of the information society economy responsible for the production, reproduction, and dissemination of knowledge and information (Machlup, 1962). In modern publications, this interpretation is found, which allows a slight change in terminology, but retains its original meaning $[9,30]$.

\section{RESULTS AND DISCUSSION}

\section{A. Analysis of the concept of "digital economy" in the national programs and projects of Russia}

Let's try to understand the essence of the definition of the digital economy in the regulatory legal acts of Russia [33]. The key to these documents is the fact that the digital economy uses digital data. The question arises: didn't the economy operate in numbers in an industrial society? It seems to us that economic activity is based on working with numbers. Without this, it is impossible even to maintain a personal economy, not to mention the country's economy. The second point that we should pay attention to is the phrase "processing large volumes." Perhaps it was meant that the digital economy allows the processing of large amounts of data, compared with the traditional economy. However, this opportunity is not provided by the digital economy as such, but by the information technologies that it uses.

The third very important, in our opinion, point that should be paid attention to is the fact that only the production process is present in the definition of the digital economy. The question is, where did the other components of the economy, such as exchange, distribution, consumption, disappear from economic activity? It turns out that the digital economy is only production, while the other elements of economic activity remain not digitalized. But this is impossible even by virtue of the laws of dialectics. Such a one-sided economy is doomed to failure. The unity of the four economic processes disappears, and, consequently, the economy as a whole.

There is also doubt in the peremptory indication in the program that digital data is a key factor in the production of various kinds of goods. But isn't the proven truth that people are the key factor in the economy. Suppose that this statement is true only for an economy in which the means of labor and all other elements of economic activity are material or spiritual in nature. Yes, in this case, without the subject of activity, the activity itself is impossible. However, is it possible in a digital economy without a human being? Who will create information support for such an activity? And again, let us say that we are 
talking about the complete automation of information processing in the digital economy. But this is just as absurd as believing that artificial intelligence will completely replace humans in the future. He can free him from routine labor that does not require creativity and spirituality. Turning to the principles and laws of dialectics, we can see that the essence of man is revealed through his generic qualities i.e. those of its properties that no creature or device claims to be humanized. This is, first of all, consciousness, language, communication and activity. No artificial intelligence system can reproduce them. This phenomenon has its own essence and its generic characteristics.

Thus, for example, P.S. Gurevich notes that if we do not take into account the generic qualities of man, which distinguish him from all other creatures on Earth, then the creation of artificial intelligence can be considered a reality [13].

In the literature on the philosophical problems of cybernetics and artificial intelligence, a consideration of the relationship between human thinking and the capabilities of computers is often replaced by the question - do machines think? Such a formulation of the problem leads to endless discussions about the capabilities of artificial intelligence $[2,3,17]$.

Before taking this or that position on this issue, it is necessary to determine the initial methodological guidelines. The most important element here is the concept of the subject, which is considered to be a person in the scientific literature and the various communities that he creates.

The violation of accepted principles in the methodology of subject-object relations leads researchers of artificial intelligence to the opinion that the technical device is capable of being a subject, i.e. to be equated with a person. J. Moore, for example, believes that the computer can be seen as the subject of decision-making [23]. It is likely that the search for the answer to the question: "Is an intelligent machine a subject" leads to two opposing points of view, each of which is difficult to prove or refute.

Turning to the methodology for determining the concept of the subject, one can see that in philosophy the subject and object are sometimes not interpreted in the strict sense. It is a matter of the fact that, as a subject, it is not himself that can be understood as being, but only the roles, functions that he performs [15].

Probably, the question should be formulated differently: "Can the artificial intelligence system play the role of the subject?" In other words, such an understanding of the role and place of intelligent machines in human social life leads to the need to introduce the concept of "quasi-subject". In this case, we remove the controversial points, because we do not put an equal sign between natural and artificial intelligence, but point out the possibility of increasing the roles of the machine, which it can fulfill as technological progress develops and in humans' decreases as the socialization is mechanized. Thus, the question remains about the limiting boundaries of human transmission of these roles to intellectual technology.
The study and modeling of human neural processes is today one of the urgent problems in the research of such areas as cognitive psychology, artificial intelligence, etc. [4].

It turns out that when adopting the national program, the authors did not take into account the subtleties and nuances of the categorical apparatus developed by scientists to determine the essence of the phenomena under study. They probably did not take into account the systematic approach, which is the fundamental basis of the methodology for developing any activity program, especially when it comes to the scale of the state.

\section{B. Analysis of the concept of "digital economy" in scientific publications}

Before using this or that category in real activity or social management, it is necessary to carefully study all aspects and boundaries of its application. Economics and social management are the very areas of real life that at the present stage cannot function effectively without strict rules and clear definitions. An economy that uses a categorical apparatus, formulated not within the framework of science, but at the level of everyday consciousness, is doomed to constant failures and crisis states. It turns out that when making decisions, management entities at all levels of the federal, regional and municipal do not have in their hands a tool for formalizing decisions in a scientific language. The absence of a strictly established terminology in the scientific revolution leads to a distortion of the meaning and essence of the phenomenon, and therefore of the decisions made.

A study of publications devoted to the analysis and comparison of different interpretations of the concepts of the digital economy and those close to it showed that, for example, the main difference in the concept of "knowledge economy" is as follows: "The main factor in the formation and development of the knowledge economy is human capital. At the same time, a sufficiently high level of development of social capital is needed. Maybe the last phrase is the key to the answer - the knowledge economy in one way or another requires the development of a person and society [26]. Now it's clear that scientists, introducing the term "knowledge economy", did not identify it with the concept of "digital economy". These are two different phenomena, but they are identified in regulatory documents.

There is still no common understanding in the scientific literature regarding the breeding of the concepts of "digital economy" and "information economy". Most often, on the pages of publications, an opinion is expressed that the digital economy is still not a separate sector of it, but an economic activity based on information technology. One way or another, the terms "information economy", "digital economy" and "knowledge economy" require correlation. If we are talking about the role of information technology in developing the competitiveness of the economy as a phenomenon of human social life, then the concepts of "information economy" and "digital economy" become identical.

In modern publications, there are increasingly common positions according to which the digital economy is the only type of economic detail that can exist in the era of information 
civilization. So, A.A. Myakishev identifies the following features of the digital economy, which, in his opinion, is the future: "... the widespread use of artificial intelligence; lack of need for unskilled labor; cars will operate without direct control of people (including cars without drivers; already today such trucks are used in the European Union and China) [24].

Indeed, this position reflects a completely different meaning of the concept of "digital economy". As we can see, here we are talking about the fact that informatisation of the economic sphere leads to the transformation of the entire economy into an information economy, when artificial intelligence works along with natural intelligence. In this regard, other questions arise and the term "digital economy" can be filled with different meanings. If we take this position, then in normative documents and programs for action it is necessary to indicate the types of subjects and their roles for which these programs are intended.

To understand the essence of the phenomenon of the digital economy, scientists conduct comprehensive research and build concepts and models of new economic relations. One of the effective methods in this case is the comparison method. So, in scientific publications, scientists conduct studies containing a comparative analysis of the material economy and the digital one. For example, B. Titov provides the following data for comparison. Apple's electronics and information technology company capitalizes at $\$ 904.6$ billion; Alphabet Inc. (Google) Internet services, applications, YouTube video hosting this figure is $\$ 782.7$ billion; Microsoft (Software Production) capitalization $-\$ 681.6$ billion, etc. The last lines in the table are Exxon Mobil - Oil production and refining - $\$ 368.5$ billion and General Electric - Production of electrical, energy, medical equipment, household appliances; transport engineering $\$ 157.9$ billion [34].

When comparing the data, it can be seen that material production is being supplanted by the digital economy sector. According to experts, it becomes the basis for the development of the economy as a whole, having a strong impact on industries that can develop in modern conditions only through informatisation. First of all, these are financial and banking activities, trade, healthcare, education, etc. [10, 18].

If we follow this logic in understanding and determining the meaning of the concept of "digital economy", then this term should be defined precisely as the sector of the economy responsible for translating economic relations into the "figure". It is no coincidence (OEDC) - the Organization for Economic Development and Cooperation that interprets the concept of "digital economy" as economic relations implemented on the basis of information technology. These relations are actualized in the trade in information products and services, for example, via the Internet [14].

The main problem of integrating the digital economy into traditional economic relations, which subsequently undergo informatisation and digitalization, is personnel issues.

The difficulty is caused not so much by the processes of informatisation of a particular field of activity, but by the solution of personnel issues. The control problem can be automated; the problem of informatisation can also be solved. Experience shows that equipping even the most up-to-date equipment, information systems of an organization or even a complex of organizations will not have positive dynamics, if the main task is not solved, the personnel are not trained i.e. People able to competently participate in the processes of the digital economy. For example, sociological studies show that Russia ranks 41 st out of 139 countries in terms of the development of informatisation institutions, the main task of which is to increase the competitiveness of the economy, as well as the quality and standard of living of the population [8].

Today, the United States and the United Kingdom are leaders in the digital economy. The digital economy in these countries occupies more than $30 \%$ of GDP [8].

Such a strong lag of Russia from world leaders in the development of the digital economy is initially seen in the legislative and regulatory documents regulating this area of economic activity. We mentioned above the main problems in them regarding terminological confusion. However the problems do not end there. Researchers also name a number of critical points in the national programs, which, in their opinion, lead to deadlocks in decision-making on the development of the digital economy in the country. V.V. Ivanov and G.G. Malinetskiy, note that the goals formulated in the program are not specified, their wording is vague and ambiguous [14]. This corollary is understandable. If ambiguous instructions are given when developing a program that is designed for an automaton or artificial intelligence system, the task will never be completed. No matter how advanced artificial intelligence, natural intelligence will always be behind it. And if vague goals are set for natural intelligence, then it is able to interpret them because of its subjectivity and make decisions that, as a result, may not correspond to the originally set goals. Thus it turns out that projects and programs aimed at developing the economy in the information society are carried out ambiguously, leading to serious crisis situations.

The main reason for problem situations in the implementation of the program is the lack of support for serious scientific research during its development.

\section{CONCLUSION}

The study showed that as a result of the lack of fundamental scientific research on the phenomenon of the digital economy in our country, a number of assumptions have developed in the field of economic and managerial activity, which have become a guide to action, which have been refuted by time and reality:

Assumption 1. The information economy and the digital economy are identical concepts.

The study showed that information technology is a tool that without a person means nothing. The digital economy involves the development of new models of business and entrepreneurship. Therefore, we are talking about completely different phenomena that are interpreted differently in the national program and other regulatory documents. 
Assumption 2. Digital economy can improve productivity.

In practice, it turns out that the introduction of the most advanced technologies in production becomes ineffective if there is no corresponding management system headed by a person.

Assumption 3. Digitalization solves the problem of lacking of qualified personnel.

But this is absurd, because intellectualization, automation and robotics, as well as digitalization, require even more highly qualified personnel to service and support such technologies.

The adoption of national programs based on an unworked categorical apparatus, without taking into account the possible negative social consequences of the introduction of artificial intelligence systems and information technologies, which scientists warn about, leads to serious problems in the economic development of the country. Concerted action is needed in the field of economics and management based on scientific research.

\section{References}

[1] R.F. Abdeev, Philosophy of information civilization. Moscow: Clinc. Gor. Tip. Publ., 2004, 94 p.

[2] S.R. Ableev, "Modeling of consciousness and artificial intelligence: limits of possibilities", Delphis, no. 85, 2016. Retrieved from: http: // www. delphis.ru/joumal/artide/modelirovanie-soznaniya-iiskusstvennyi-intellekt-predely-vozmozhnostei

[3] A.Yu. Alekseev, "Philosophy of Artificial Intelligence", Bull. of the Russ. Philos. Society, no. 1, pp. 105-109, 2005.

[4] A. Ashman, R. Conway, An Introduction to Cognitive Education: Theory and Applications. Routledge, 2014, 268 p.

[5] D. Bell, The Coming Post-Industrial Society: An Experience of Social Forecasting. Moscow: Acad., 2004, 783 p.

[6] M. Castells, The power of communication, 2rd ed. augmented. Moscow: Publ. High school of Econ., 2017, 590 p.

[7] Development Strategy of the Information Society in the Russian Federation for 2017-2030, 2018. Retrieved from: https://www.garant.ru/products/ipo/prime/doc/71570570/

[8] Federal State Statistics Service, Russia in numbers, 2019. Retrieved from: https://gks.ru/bgd/regl/b19_11/Main.htm

[9] A.A. Gazhur, I.N. Lukiyanchuk, "Trends of development of the sphere of services in Russia", Proc. of the Voronezh State Univer. of Engineer. Technol., vol. 80, no. 3, pp. 444-450, 2018. Retrieved from: https://doi.org/10.20914/2310-1202-2018-3-444-450

[10] M.L. Gruzdeva, N.I. Tukenova, "Analysis of the current state of research and development in the field of building information and educational environments of higher educational institutions", Vestnik of Minin University, vol. 7, vo. 2(27), 2019. DOI: https://doi.org/10.26795/95/2307-1281-2019-7-2-1

[11] E.V. Gryaznova, "Methods of cognition and categories of the philosophy of science", NB: Pedag. and ed., no. 3, pp. 49-68, 2014.

[12] E.V. Gryaznova, A.A. Vladimirov, S.M. Maltceva, A.G. Goncharuk, N.V. Zanozin, "Problems of Virtualization and Internetization of Social Space", Lecture Notes in Networks and Systems, no. 91, pp. 119-124, 2020

[13] P. Gurevich, "Apophatic project of man", Quest. of philos., no. 8, pp. $42-53,2013$
[14] V.V. Ivanov, G.G. Malinetskiy, "Strategic priorities of the digital economy", Strategic priorities, vol. 3, no. 15, 2017.

[15] M. Kagan, "Science and Technology in the Past, Present and Future", Leonardo, vol. 27, no. 5, 1994.

[16] N.I. Khosroeva, "Human capital as a factor in the formation of the knowledge economy", Azimuth of Scientific Research: Economics and Managment, vol. 6, no. 4(21), pp. 255-258, 2017.

[17] A.V. Kolesnikov, "On the nature of the "I" and thinking machines", Polygnosis, no. 4, pp. 138-140, 2000.

[18] S.N. Kuznetsova, V.P. Kuznetsov, E.P. Kozlova, Y.S. Potashnik S.D. Tsymbalov, "Transformational Period of Russian Development in the Digital Economy", Lecture Notes in Networks and Syst., no. 91, pp. 663-669, 2020.

[19] F. Machlup, The Production and Distribution of Knowledge in the United States. New Jersey: PrincetonUnivers, Press, 1962, 108 p

[20] "Management Development in the Transition to a Digital Economy", p. 22, 2017 [Materials of the Xth All-Russ. Sci.-pract. Conf, Perm, PGNIU]. (Perm, 7 December 2017). Publ. Perm. state nat. research un-t.

[21] M. McLuhan, The Gutenberg Galaxy. Becoming a man typing. Moscow: Acad. project Publ., 2015, 443 p.

[22] N.N. Moiseev, The fate of civilization. The path of the mind. Moscow: Yaz. Of the Russ. Culture Publ., 2000, 223 p.

[23] J. Moor, Are there decisions computers should never make? Ethica issues in the use of computers. Belmont, 1985, pp. 120-130.

[24] A.A. Myakishev, Digital economy is the only economy of our time. In the book: Digital transformation of education, pp. 468-472, 2018 [Electronic collection of abstracts of reports of the 1st sci. and pract. Conf.]

[25] N. Negroponte, Being Digital. New York: Alfred A. Knopf, Inc.; Vintage Books, 1996, $324 \mathrm{p}$

[26] A.V. Ponachugin, Yu.N. Lapygin, "Digital educational resources of the university: design, analysis and examination", Vestnik of Minin University, vol. 7, no. 2, 2019. DOI: https://doi.org/10.26795/23071281-2019-7-2-5

[27] M. Porat, The Information Economy. Washington, D.C, U.S. Government Printing Office, 1977, 200 p.

[28] V.V. Pyatkin, A.I. Kolchin, "From the information society to the digita economy or to the knowledge economy?", Bull. of Modern Res. vol. 7.1 , no. 22 , pp. 244-246, 2018.

[29] A. Rakitov, Information, science, technology in global historical changes. Moscow: Direct Media Publ., 2014, 104 p.

[30] Y.A. Salikov, I.V. Logunova, I.V. Kablashova, "Trends in human resource management in the digital economy", Proc. of the Voronezh State Univer. of Engineer. Technol., vol. 81, no. 2, pp. 393-399, 2019. DOI: https://doi.org/10.20914/2310-1202-2019-2-393-399

[31] M.A. Sukhareva, "From the concept of a post-industrial society to the concept of a knowledge economy and a digital economy: a critica analysis of the terminological field", Public Administrat., Electr. Bull., no. 68 , pp. $445-464,2018$

[32] K.A. Tatarinov, "The value of customer loyalty for a company in an information economy", Azimuth of Scientific Research: Economics and Managment, vol. 8, no. 1(26), pp. 302-306, 2019.

[33] The National program of the Digital Economy of the Russian Federation, 2018. Retrieved from: https://digital.gov.ru/ru/activity/ directions/858/

[34] B. Titov, Russia: from digitalization to the digital economy, 2016. Retrieved from: http://stolypin.institute/wp-content/uploads/2018/09/ issledovanie_tsifrovaya-ekonomika-14-09-18-1.pdf;

[35] Worldwide review of the implementation of the Industry 4.0 concept for 2016. Retrieved from: https://www.pwc.ru/ru/technology/assets/ global_industry-2016_rus.pdf.

[36] E. Toffler, The Third Wave. Moscow: AST Publ., 2009, 795 p. 